\title{
Intoxicação espontânea e experimental por nitrato/nitrito em bovinos alimentados com Avena sativa (aveia) e/ou Lolium spp. (azevém) ${ }^{1}$
}

\author{
Fernanda Jönck ${ }^{2}$, Aldo Gava ${ }^{2 *}$, Sandra Davi Traverso², Joelma Lucioli ${ }^{3}$, Fernando \\ Henrique Furlan ${ }^{4}$ e Edgar Gueller ${ }^{5}$
}

\begin{abstract}
Jönck F., Gava A., Traverso S.D., Lucioli J., Furlan F.H. \& Gueller E. 2013 [Spontaneous and experimental poisoning by nitrate/nitrite in cattle fed Avena sativa (oat) and/or Lolium spp. (ryegrass).] Intoxicação espontânea e experimental por nitrato/nitrito em bovinos alimentados com Avena sativa (aveia) e/ou Lolium spp. (azevém). Pesquisa Veterinária Brasileira 33(9):1062-1070. Departamento de Medicina Veterinária, Centro de Ciências Agroveterinárias, Universidade do Estado de Santa Catarina, Lages, SC 88520-000, Brazil. E-mail: a2ag@cav.udesc.br

Epidemiological data, clinical and pathological findings of the spontaneous andexperimental poisoning by nitrate and nitrite in cattle fed oats (Avena sativa) and/or ryegrass (Lolium spp.), diphenylamine test, and the nitrate content in the samples of the pasture where the outbreaks occurred, are described. The disease occurs in different regions of the State of Santa Catarina, in which pastures have exuberant growth, after receiving excessive amounts of chemical and/or organic fertilizer, mainly when raining occurs after a period of dry wheather. The animals grazing these pastures quickly develop brown mucosa, tachypnea, staggering gait, frequent urination, bloating, lateral recumbency and death in few minutes or hours. At necropsy of four animals that died spontaneously, the main lesions found were brown mucosa, dark color of the blood (chocolate), intense red color of the skeletal muscles and of the left part of the myocardium. The experimental reproduction of the disease was performed in seven cattle, with pastures from four farms where the disease occurred. The animals were fed with fresh oats and ryegrass and/or hay of it. Four animals died, two became ill and recovered, and one was treated with $2 \mathrm{mg} / \mathrm{kg}$ per body weight of methylene blue $1 \%$, and one cattle did not show changes. Clinical signs and lesions of the diseased animals that died were similar to natural cases. Microscopic changes were not observed in spontaneous and experimental poisoning. The diphenylamine test was positive in all the farms where the outbreaks occurred. The chemical analysis performed on samples of the pastures from several farms, in which outbreaks of the disease occurred, ranged from 0.30 to $3.36 \%$ of nitrate in the dry matter. The disease is associated with the ingestion of oats and/or ryegrass pastures heavily fertilized, which accumulates high levels of nitrate after a period of rain and is characterized by rapid breathing, dark-colored blood, brown mucous and rapid death.
\end{abstract}

INDEX TERMS: Nitrate/nitrite, methemoglobinaemia, oat, Avena sativa, ryegrass, Lolium spp., diphenylamine test.

${ }^{1}$ Recebido em 26 de março de 2013.

Aceito para publicação em 20 de junho de 2013.

Dissertação de Mestrado do primeiro autor, defendida na Universidade do Estado de Santa Catarina (UDESC), Lages, SC 88520-000, Brasil.

${ }^{2}$ Laboratório de Patologia Animal, Departamento de Medicina Veterinária, Centro de Ciências Agroveterinárias, UDESC, Av. Luiz de Camões 2090, Bairro Conta Dinheiro, Lages, SC 88520-000, Brasil. *Autor para correspondência: $\underline{\text { 22ag@cav.udesc.br }}$

\footnotetext{
${ }^{3}$ Hospital Escola Veterinário, Fundação Universidade Regional de Blumenau (FURB), Rua Samuel Morse 768, Bairro Fortaleza Alta, Blumenau, SC 89058-010, Brasil.

${ }^{4}$ Hospital Veterinário-Laboratório de Patologia Veterinária, Av. Alexandre Ferronato 1200, Bairro Distrito Industrial, Sinop, MT 8550-000, Brasil.

${ }^{5}$ Médico Veterinário autônomo, Rua Rodolfo Rofner 44, Treze Tílias, SC 9650-000, Brasil.
} 
RESUMO.- Descrevem-se os dados epidemiológicos, sinais clínicos e lesões da intoxicação espontânea e experimental por nitrato e nitrito em bovinos alimentados com pastagens de Avena sativa (aveia) e/ou Lolium spp (azevém). A enfermidade ocorre em diferentes regiões do Estado de Santa Catarina, quando as pastagens tem crescimento exuberante, após receberem quantidades excessivas de adubo químico e/ou orgânico, principalmente quando ocorrem condições climáticas de seca e posteriormente chuva. Os animais em contato com essas pastagens desenvolvem rapidamente mucosas de coloração marrom, taquipnéia, andar cambaleante, micção frequente, timpanismo, decúbito lateral e morte em poucos minutos, ou recuperação algumas horas após. Na necropsia de quatro animais que adoeceram espontaneamente, as principais alterações encontradas foram a coloração marrom das mucosas, a cor escura do sangue (cor de chocolate) e a coloração vermelho intensa da musculatura esquelética e do miocárdio esquerdo. A reprodução experimental da doença foi realizada em sete bovinos, com pastagens de quatro propriedades onde ocorreu adoença. Aveia e/ou azevém verdes e sob a forma de feno foram administradas aos bovinos. Destes bovinos quatro morreram, dois adoeceram e se recuperam, um naturalmente e outro com a aplicação de azul de metileno a $1 \%$, na dose de $2 \mathrm{mg} / \mathrm{kg} /$ peso vivo, e um bovino não apresentou alterações. Os sinais clínicos observados e as lesões nos animais que adoeceram e morreram foram idênticos aos casos naturais. Alterações microscópicas não foram observadas nos casos naturais e experimentais. 0 teste da difenilamina nas amostras de pastagens onde ocorreram os surtos resultou positivo em todas as propriedades. A análise bromatológica realizada em amostras coletadas de várias propriedades em que ocorreram surtos revelou de 0,30 a 3,36\% de nitrato na matéria seca. A enfermidade caracterizou-se principalmente por respiração ofegante, sangue de coloração escura, mucosas de coloração marrom e morte rápida dos bovinos e está relacionada á ingestão de pastagens de aveia e/ou azevém super adubados, que acumularam alto teor de nitrato, após um período de chuvas precedido de seca.

TERMOS DE INDEXAÇÃO: Nitrato/nitrito, methemoglobina, aveia, Avena sativa, azevém, Lolium spp., teste da difenilamina.

\section{INTRODUÇ̃̃o}

A utilização de pastagens cultivadas tem aumentado significativamente nos últimos anos em Santa Catarina, particularmente no Oeste, no Planalto Serrano e no Alto Vale do Itajaí, o que tem contribuído para o aparecimento de enfermidades anteriormente não observadas. Essas pastagens na maioria das vezes são constituídas por Avena sativa (aveia) e/ou Lolium spp. (azevém). Nessas condições, mortes de bovinos são freqüentes. A mortalidade de bovinos que pastoreiam sobre gramíneas cultivadas em solos super adubados é conhecida em outros países (Newsom et al. 1937, Bradley et al. 1939, O’Hara \& Fraser 1975, Rosenberger 1975, Carrigan \& Gardner 1982, Riet-Alvariza 1993, McKenzie et al. 2004) e estas mortes geralmente estão relacionadas a plantas com alto teor de nitrato/nitrito.

Os nitratos são absorvidos do solo pelas raízes das plan- tas e incorporados normalmente aos tecidos como aminoácidos, proteínas e outros compostos nitrogenados. 0 local primário para conversão do nitrato nesses produtos são as folhas verdes em crescimento (Ozmen 2003). Nitratos e nitritos podem estar presentes em altas concentrações em alguns alimentos, particularmente em gramíneas forrageiras no início do estágio vegetativo, fertilizadas com grandes quantidades de nitrogênio (Wright \& Davison 1964; Radostits et al. 2002; Kozloski 2009).

No trato digestivo dos ruminantes, os nitratos são reduzidos a nitritos pelos microorganismos ruminais para a síntese de proteína microbiana e posteriormente à amônia para ser eliminada e utilizada para o metabolismo das bactérias e protozoários ruminais (Kozloski 2009). Dependendo de uma série de fatores, sobretudo da quantidade de nitratos ingeridos, da flora do rumem ou da dieta do animal, o processo de redução de nitratos à amônia é inadequado, ocorre o acumulo de nitrito (Wang et al. 1961, Allison 1978, Kozloski 2009). Uma vez acumulado no rumem, o nitrito é absorvido pelos capilares ruminais e chega à corrente sanguínea. 0 nitrito oxida a molécula heme da hemoglobina, que é oxidada do estado ferroso $\left(\mathrm{Fe}^{2+}\right)$ para o estado férrico $\left(\mathrm{Fe}^{3+}\right)$. A forma oxidada da hemoglobina é chamada de metemoglobina, que por sua vez não carreia oxigênio $\left(\mathrm{O}_{2}\right)$, o que resulta nos sinais clínicos característicos de hipóxia e anóxia tecidual (Rosenberger 1975, Radostits et al. 2002).

No Brasil há relato de intoxicação por nitrato/nitrito no sertão da Paraíba com a ingestão de capim-mandante (Echinochloa polystachya) e capim-elefante (Pennisetum purpureum) (Medeiros et al. 2003).

Este trabalho teve por objetivo avaliar os aspectos epidemiológicos, clínicos e lesionais de bovinos que adoeceram e morreram espontaneamente em pastagens de aveia (Avena sativa) e/ou azevém (Lolium spp.), de reproduzir experimentalmente a enfermidade e de avaliar as concentrações de nitrato nas pastagens.

\section{MATERIAL E MÉTODOS}

0 trabalho foi dividido e desenvolvido em quatro etapas: acompanhamento da doença espontânea, a sua reprodução experimental, a realização do teste da difenilamina e da análise de nitrato nas pastagens.

Doença espontânea. A doença espontânea consistiu da coleta de históricos e de dados epidemiológicos, e da realização de necropsias de bovinos que morreram da doença. Os históricos foram obtidos de médicos veterinários e produtores dos municípios de Rio do Sul, Pouso Redondo, Seara, Faxinal dos Guedes, Chapecó, Concórdia, Água Doce, Treze Tílias, Otacílio Costa, Petrolândia e Lages, SC. Paralelamente, foram visitadas 12 propriedades rurais, seis no município de Seara, duas em Faxinal dos Guedes, uma em Petrolândia, uma em Rio do Sul, uma em Pouso Redondo e uma em Lages. As visitas foram feitas durante os meses de junho a outubro, que correspondem ao período vegetativo da aveia e do azevém, época em que foram realizadas o teste da difenilamina e a coleta de amostras de pastagem para posterior análise bromatológica. Adicionalmente foram coletadas amostras de água que os animais consumiam dos reservatórios da Propriedade 2 em Pouso Redondo e da Propriedade 6 em Seara.

${ }^{6}$ Projeto de pesquisa aprovado no comitê de ética de experimentação animal (CETEA) da Universidade do Estado de Santa Catarina (CAV/ UDESC, Protocolo 1.08.07). 
Quadro 1. Delineamento experimental em relação aos bovinos utilizados, pastagens, sua origem, quantidade e período de ingestão

\begin{tabular}{cccccc}
\hline $\begin{array}{c}\text { No } \\
\text { bov. }\end{array}$ & Raça & Sexo & $\begin{array}{c}\text { Peso } \\
\text { (kg) }\end{array}$ & $\begin{array}{c}\text { Tipo de pastagem/pro- Total de planta inge- } \\
\text { priedade da coletada }\end{array}$ & $\begin{array}{c}\text { rida (kg)/período de } \\
\text { ingestão (dias) }\end{array}$ \\
\hline 131 & Jersey & Macho & 75 & Azevém verde/prop.2 & $96,8 / 10$ dias \\
136 & HPB & Macho & 110 & Aveia verde/prop.1 & $90 / 5$ dias \\
137 & Jersey & Macho & 105 & Feno de azevém/prop.2 & $8.24 / 6$ dias \\
138 & HPB & Fêmea & 272 & Feno de azevém/prop.2 & $4.64 / 10$ horas \\
130 & HPB & Macho & 120 & Feno de azevém/prop.2 & $4,4 / 3$ dias \\
140 & Mestiço Macho & 108 & Feno de aveia/prop.7 & $1,4 / 9$ horas \\
141 & Mestiço Macho & 109 & Aveia verde/prop.3 & $68,85 / 3$ dias
\end{tabular}

Reprodução experimental. ${ }^{6}$ Foram coletadas amostras de aveia e azevém de quatro propriedades que tiveram casos de intoxicação e fornecidas a sete bovinos nas dependências do Laboratório de Patologia Animal no Centro de Ciências Agroveterinárias da Universidade do Estado de Santa Catarina (CAV-UDESC), na forma verde e na forma de feno. Na forma verde as amostras após coletadas eram conservadas em câmara fria e para obtenção de feno as amostras foram secadas a sombra. A pastagem era fornecida in natura no cocho ad libitum. Os experimentos realizados estão delineados no Quadro 1.

Os animais experimentais eram mantidos em baias individuais de alvenaria, com água ad libitum, e avaliados clinicamente várias vezes ao dia após o início da ingestão das pastagens e observados até a morte ou recuperação. Foram avaliadas alterações de comportamento, de coloração de mucosas, dos movimentos respiratórios, cardíacos e ruminais, o aspecto das fezes e da freqüência de micções.

Os animais que morreram, foram necropsiados; foram coletados fragmentos de todas as vísceras que foram fixadas em formalina a $10 \%$. As amostras foram processadas rotineiramente e coradas pela técnica de hematoxilina e eosina (HE) (Prophet et al. 1992) para observação em microscópio ótico.

Em um bovino (Bov. 140) experimental foi aplicado azul de metileno a $1 \%$, na dose de $2 \mathrm{mg}$ por $\mathrm{kg}$, por via endovenosa, quando este manifestou os sinais clínicos da doença.

Teste da difenilamina. Em propriedades onde ocorreu a enfermidade e onde não houve históricos da doença, e que foram visitadas, realizou-se o teste da difenilamina. Este consiste na obtenção de três gotas de extrato vegetal das folhas verdes de aveia ou azevém obtidas por pressão manual, expostas sobre lâminas de vidro, e sobre estas adicionada uma gota do reagente. A reação foi considerada positiva, quando apareceu em menos de 10 segundos coloração azul intensa.

A solução de difenilamina utilizada nos testes era composta de $0,5 \mathrm{~g}$ de difenilamina, $20 \mathrm{ml}$ de água destilada e ácido sulfúrico concentrado em quantidade para completar $100 \mathrm{ml}$ (Radostits et al. 2002).

Análise de nitrato nas pastagens e na água. As amostras de pastagens foram coletadas em propriedades onde ocorreu a enfermidade e em propriedades com histórico da ocorrência de sinais clínicos compatíveis com a doença. Foram colhidas amostras de diferentes áreas dos piquetes onde ocorreram surtos. Estas foram secadas a sombra e armazenadas em sacos plásticos.

As amostras foram analisadas no Laboratório de Química e Fertilidade do Solo do CAV-UDESC usando o método de destilação a vapor (Tedesco et al. 1995). O procedimento utiliza a extração por cloreto de potássio $(\mathrm{KCl}) 1 \mathrm{Molar}(\mathrm{M})$ e titulação com ácido sulfúrico $\left(\mathrm{H}_{2} \mathrm{SO}_{4}\right)$ a $0,0025 \mathrm{M}$, determinando em ppm ou mg/kg e percentual de amônio + nitrito + nitrato mineral $\left(\mathrm{N}-\mathrm{NO}_{3}\right)$.

Na determinação do nitrato por destilação, o valor encontrado é referente a concentração de nitrogênio $(\mathrm{N})$ que faz parte do nitrato $\left(\mathrm{N}-\mathrm{NO}_{3}\right)$. Para converter para nitrato $\left(\mathrm{NO}_{3}\right)$, multiplica-se este valor por 4,43 . 0 peso molecular do nitrato é 62 e do nitrogênio é 14 . Para cada $14 \mathrm{ppm}$ de nitrogênio há $62 \mathrm{ppm}$ de nitrato. Para cada 1ppm de $\mathrm{N}$ temos 4,43 de nitrato.

Adicionalmente, foram coletadas amostras dos reservatórios de água, de duas propriedades (Propriedade 2 em Pouso Redondo e na Propriedade 6, em Seara) aos quais os animais tinham acesso e que continham grande quantidade de matéria orgânica. As amostras foram processadas pela ENOPS Engenharia Ltda, responsável pelas análises de água da Secretaria Municipal de Águas e Abastecimento de Lages, SC (SEMASA).

\section{Doença espontânea}

\section{RESULTADOS}

De acordo com levantamento efetuado a partir de informações registradas no Setor de Patologia Animal (CAV/ UDESC), dois surtos de intoxicação por nitrato/nitrito em bovinos foram diagnosticados no município de Rio do Sul e Pouso Redondo, SC, nos meses de junho a agosto de 2006. Na Propriedade 1 (Rio do Sul), a pastagem era constituída por aveia (Avena sativa) e azevém (Lolium spp.). De um total de 78 vacas adoeceram 12 animais (15,38\%); dessas 10 morreram $(12,82 \%)$, dos quais dois foram necropsiados. Na Propriedade 2 (Pouso Redondo), de 75 bovinos mantidos em pastagem constituída somente por azevém, 19 adoeceram $(25,33 \%)$, oito morreram $(10,66 \%)$ e um foi necropsiado. Em ambas as propriedades, as pastagens foram previamente adubadas com ureia na proporção de 150 $\mathrm{kg}$ por hectare. A enfermidade começou uma semana após a ocorrência de chuva, precedida de um período seco. Nas duas propriedades o reservatório de água consumida pelos animais continha grande quantidade de matéria orgânica.

De acordo com informações obtidas, a enfermidade ocorreu entre 15 e 20 minutos após a ingestão de água e caracterizou-se por mucosas de coloração marrom, taquipnéia, andar cambaleante, micção frequente, timpanismo, decúbito lateral e morte em poucos minutos, ou recuperação algumas horas após. Adicionalmente duas vacas que apresentaram esses sinais e não morreram, abortaram no dia seguinte. Nenhum animal clinicamente doente foi acompanhado por veterinário.

Nos três bovinos necropsiados, os principais achados de necropsia consistiram de sangue escuro (Fig.1A), não coagulável, e em contato com superfícies, as manchava como se fossem pinceladas. Os músculos cardíaco e esqueléticos tinham coloração vermelho intenso (Fig.1B), e órgãos claros, como pulmão e SNC apresentavam-se levemente marrom (Fig.1C e 1D). Microscopicamente, nenhuma alteração foi observada.

Posteriormente à realização do diagnóstico de intoxicação por nitrato/nitrito, 14 bovinos, três da Propriedade 1 e onze da Propriedade 2, que manifestaram os sinais clínicos da doença, foram tratados com $4 \mathrm{mg} / \mathrm{kg}$ de azul de metileno na concentração de 1\%, por via intravenosa, pelo proprietário. Todos se recuperaram, em média, após trinta minutos.

Na Propriedade 1, o quadro clínico cessou após os animais terem sido transferidos para um piquete que não havia sido adubado com ureia. Os sinais clínicos de metemoglobinemia continuaram na Propriedade 2, mesmo após a 

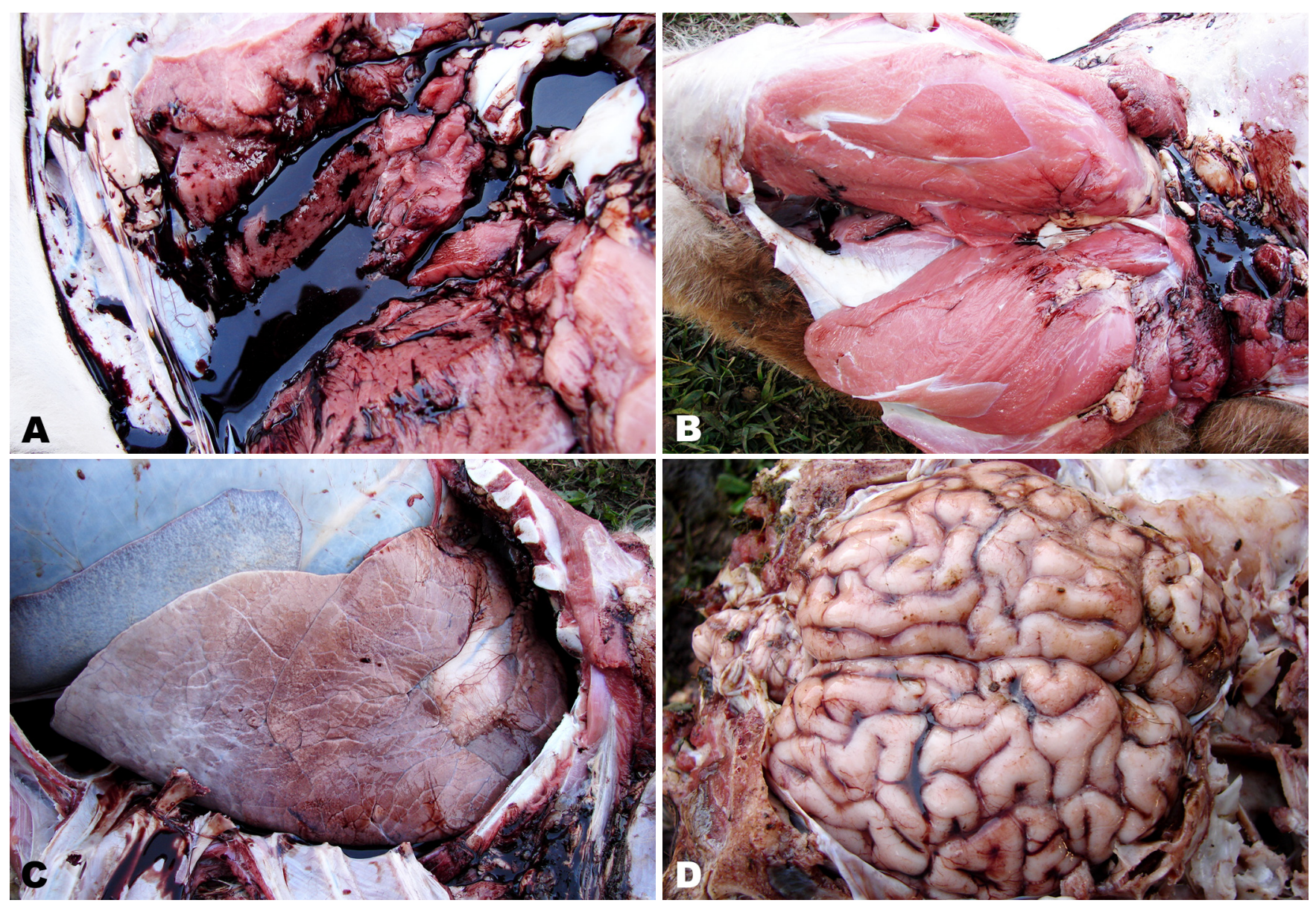

Fig.1. Intoxicação espontânea por nitrato/nitrito em bovinos, Propriedade 2. (A). Sangue escuro (cor de chocolate). (B) Musculatura esquelética vermelha intensa. (C,D) Pulmões e SNC com tonalidade marrom.

ingestão do rebrote do azevém que havia sido roçado. A enfermidade só desapareceu após deslocamento dos animais para outra área com pastagem não cultivada.

A avaliação bromatológica de quatro amostras de aveia e azevém coletadas nas duas propriedades revelaram teores de nitrato que variaram de 2,33 a 3,36\%. A dosagem de nitrato nas amostras de água coletadas do reservatório da Propriedade 2 , realizada no intervalo de uma semana, revelou a concentração de 6,6ppm e 7,2ppm de nitrato $\left(\mathrm{NO}_{3}\right)$, na primeira e segunda coleta, respectivamente.

Nos anos subsequentes de 2007, 2008 e 2009 uma enfermidade de bovinos com sinais clínicos compatíveis com intoxicação por nitrato/nitrito foi observada em vários municípios do estado, principalmente em Seara, Faxinal dos Guedes, Chapecó, Concórdia, Água Doce, Treze Tílias, Otacílio Costa, Petrolândia e Lages. Informações obtidas de veterinários e produtores caracterizaram a enfermidade como uma doença de aparecimento rápido, que ocorria em vacas produtoras de leite. Na maioria dos casos as vacas eram encontradas mortas poucas horas após a introdução dos animais em áreas constituídas por aveia e/ou azevém. Alguns produtores relataram que ao recolher as vacas, algumas manifestavam respiração ofegante que se agravava rapidamente, urinavam com frequência, a conjuntiva tinha coloração marrom e a morte ocorria entre 15 a 20 minutos. Alguns veterinários que observaram animais clinicamen- te doentes, confirmaram as informações de produtores e acrescentaram que os animais tinham o sangue de coloração escura, também visível à necropsia, durante a qual se percebia um odor forte.

As pastagens eram constituídas por aveia e algumas por azevém, ou consorciadas (aveia + azevém), e tinham crescimento exuberante. Tinham sido adubadas com matéria orgânica, principalmente com esterco de suínos (em sete propriedades), de aves (em uma propriedade), e com uréia (duas propriedades). Os detalhes sobre as informações de produtores obtidas durante a visita às propriedades onde ocorreram surtos da enfermidade constam no Quadro 2.

A avaliação bromatológica das amostras das pastagens revelaram teores de nitrato que oscilaram de 3003,54 ppm a 7911,98 ppm por quilo de matéria seca (Quadro 2). A concentração de nitrato na água coletada no município de Seara (Propriedade 6) foi de 8,5ppm. Os testes de difenilamina realizados com amostras de folhas verdes de pastagens onde ocorreram surtos da enfermidade, resultaram todos positivos (Quadro 2) (Fig.2). Amostras coletadas de propriedades sem a enfermidade tiveram resultado negativo.

\section{Reprodução experimental.}

Dos sete bovinos utilizados para experimentação, quatro morreram (Bov.136, 137, 138 e 139), dois se recupe- 
Quadro 2. Identificação das propriedades visitadas e municípios em que ocorreram os surtos, tipo de pastagem utilizada, total de bovinos, número de bovinos doentes e bovinos mortos por propriedade, adubação utilizada, teores de nitrato em ppm e em percentagem nas amostras de pastagens obtidos pela destilação a vapor, e resultados do teste da difenilamina nas pastagens, por propriedade

\begin{tabular}{|c|c|c|c|c|c|c|}
\hline Propr. & Pastagem & $\begin{array}{l}\text { Total de animais } / \mathrm{n}^{0} \\
\text { doentes } / \mathrm{n}^{\circ} \text { mortos }\end{array}$ & Tipo de abubação & $\begin{array}{c}\mathrm{mg} / \mathrm{kg} \text { ou ppm } \\
\left(\mathrm{NO}_{3}\right)\end{array}$ & $\begin{array}{c}\% \\
\left(\mathrm{NO}_{3}\right)\end{array}$ & $\begin{array}{l}\text { Teste da dife- } \\
\text { nilamina }\end{array}$ \\
\hline \multicolumn{7}{|c|}{ Rio do Sul } \\
\hline 1 & Aveia + Azevém & $78 / 12 / 10$ & Adubação química (NPK) + Ureia & 33616,00 & 3,36 & Não realizado \\
\hline \multicolumn{7}{|c|}{ Pouso Redondo } \\
\hline 2 & Azevém & $75 / 19 / 8$ & Adubação química (NPK) + Ureia & 23340,00 & 2,33 & Não realizado \\
\hline \multicolumn{7}{|c|}{ Seara } \\
\hline 3 & Aveia & $21 / 1 / 1$ & Esterco de suínos & 4775,54 & 0,4784 & Positivo \\
\hline $3 *$ & Aveia & $21 / 1 / 1$ & Esterco de suínos & 4394,56 & 0,4385 & Positivo \\
\hline 4 & Aveia e azevém & $12 / 4 / 1$ & Esterco de suínos & 5409,03 & 0,5405 & Positivo \\
\hline 5 & Aveia & $18 / 2 / 1$ & Esterco de suínos + Nitrato de amônio & 5732,43 & 0,5715 & Positivo \\
\hline 6 & Aveia & $23 / 2 / 1$ & Esterco de suínos & 7911,98 & 0,793 & Positivo \\
\hline 7 & Aveia & $20 / 1 / 1$ & Esterco de suínos & 7911,98 & 0,793 & Positivo \\
\hline 7* & Aveia & $20 / 1 / 1$ & Esterco de suínos & 4288,24 & 0,443 & Não realizado \\
\hline 8 & Aveia & $16 / 1 / 1$ & Esterco de aves & 5218,54 & 0,5227 & Positivo \\
\hline \multicolumn{7}{|c|}{ Faxinal dos Guedes } \\
\hline 9 & Aveia & $26 / 2 / 2$ & Esterco de suínos & 3003,54 & 0,3012 & Positivo \\
\hline 10 & Aveia & $23 / 8 / 8$ & Esterco de suínos & 5001,47 & 0,5006 & Positivo \\
\hline \multicolumn{7}{|c|}{ Petrolândia } \\
\hline 11 & Azevém & $45 / 8 / 8$ & Adubação química (NPK $\left.{ }^{* * *}\right)$ + uréia & Não realizado & Não realizado & Positivo \\
\hline \multicolumn{7}{|c|}{ 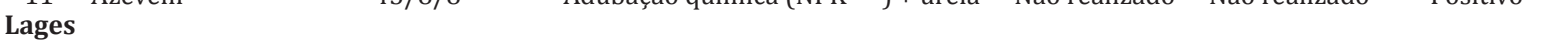 } \\
\hline 12 & Aveia & $45 / 2 / 2$ & Adubação química (NPK) + uréia & Não realizado & Não realizado & Não realizado \\
\hline 13 & Aveia & $25 / 5 / 0$ & Esterco de aves & 4088,89 & 0,4076 & Positivo \\
\hline \multicolumn{7}{|c|}{ Campo Belo } \\
\hline 14 & Aveia & $15 / 1 / 0$ & Adubação química (NPK) +uréia & 4545,18 & 0,4563 & Positivo \\
\hline
\end{tabular}

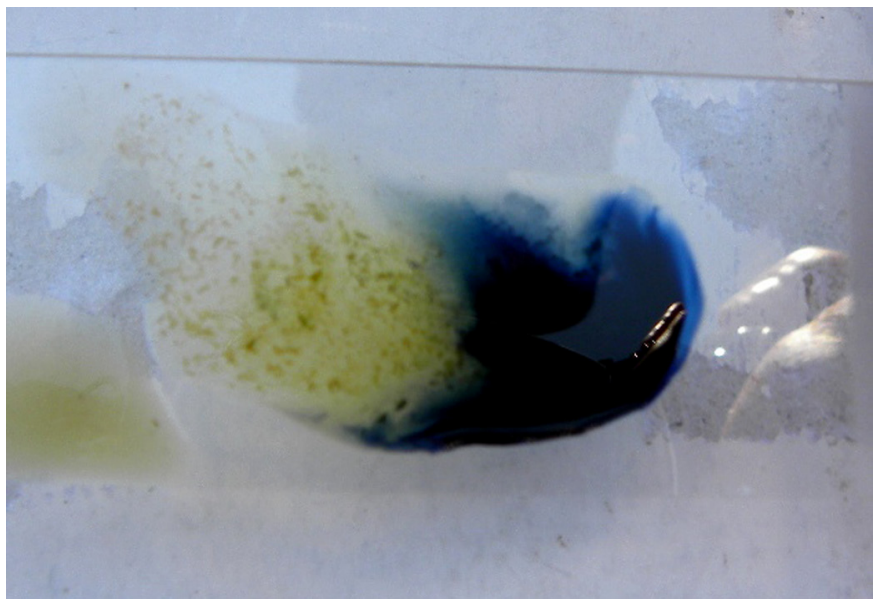

Fig.2. Teste da difenilamina. Reação positiva.

raram (Bov. 131 e 140) e um não adoeceu (Bov. 141). Dos quatro animais que morreram, três (Bov. 136, 137 e 139) morreram durante a noite e não foram observadas alterações clínicas prévias. Um bovino ( $\mathrm{n}$ o 138), apresentou de forma rápida, cansaço, mucosas marrons, taquipnéia, taquicardia, incoordenação, decúbito com dificuldade de se levantar e morte 20 minutos após o início dos sinais. $\mathrm{Na}$ necropsia, todos os animais em experimentação apresentavam as mucosas marrons (Fig.3A), o sangue de coloração escura, pulmões e o SNC tinham tonalidade marrom. Dois bovinos ( $\mathrm{n}-137$ e 138) apresentaram a musculatura esquelética e o miocárdio esquerdo de coloração vermelho intenso. 0 Bovino 139 , apresentou a mucosa do abomaso avermelhada (Fig.3B). Em todos os animais experimentais que morreram, não foram observados lesões microscópicas.

0 bovino $n^{\circ} 140$, que recebeu feno de aveia, administra-

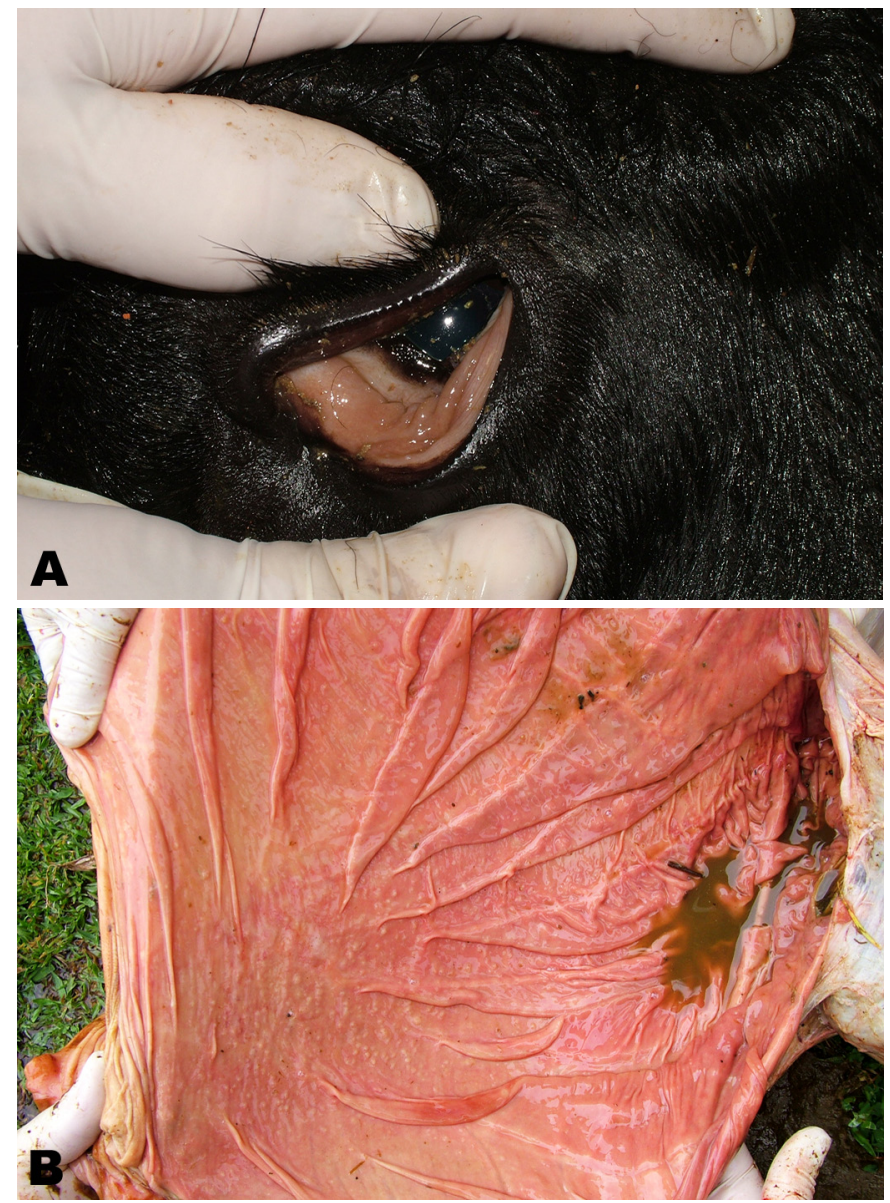

Fig.3. Intoxicação experimental por nitrato/nitrito em bovinos. (A) Mucosa ocular marrom (Bovino 136). (B) Abomaso com mucosa avermelhada (Bovino 139). 
Quadro 3. Número do bovino, peso, tipo de pastagem e número da propriedade, quantidade de planta ingerida e tempo de ingestão, principais sinais clínicos e evolução, na intoxicação experimental por nitrato/nitrito

\begin{tabular}{|c|c|c|c|c|c|}
\hline $\begin{array}{c}\text { Bovino } \\
\mathrm{n}^{\underline{0}}\end{array}$ & $\begin{array}{l}\text { Peso } \\
(\mathrm{kg})\end{array}$ & $\begin{array}{l}\text { Tipo de pastagem } / \mathrm{n}^{\circ} \\
\text { da propriedade }\end{array}$ & $\begin{array}{l}\text { Total planta ingerida }(\mathrm{kg}) / \\
\text { período de ingestão (dias) }\end{array}$ & Principais sinais clínicos & Evolução \\
\hline 131 & 75 & Azevém verde/2 & $96,8 / 10$ dias & $\begin{array}{c}\text { Mucosas levemente marrom, lacri- } \\
\text { mejamento, diarréia }\end{array}$ & Recuperação \\
\hline 136 & 110 & Aveia verde/1 & $90 / 5$ dias & Não observados & Morte \\
\hline 137 & 105 & Feno de azevém/2 & $8,24 / 6$ dias & Não observados & Morte \\
\hline 138 & 272 & Feno de azevém/2 & $4,64 / 10$ horas & $\begin{array}{l}\text { Mucosas marrom, taquipnéia, taqui- } \\
\text { cardia, incoordenação, decúbito }\end{array}$ & Morte \\
\hline 130 & 120 & Feno de azevém/2 & $4,4 / 3$ dias & Não observados & Morte \\
\hline 140 & 108 & Feno de aveia/7 & $1,4 / 9$ horas & $\begin{array}{l}\text { Mucosas marrom, taquipnéia, taqui- } \\
\text { cardia, incoordenação, decúbito }\end{array}$ & $\begin{array}{l}\text { Recuperação } 10 \text { minutos após tra- } \\
\text { tamento com azul de metileno }\end{array}$ \\
\hline 141 & 109 & Aveia verde/3 & $68,85 / 3$ dias & Não apresentou sinais clínicos & - \\
\hline
\end{tabular}

do por via oral durante 9 horas, proveniente da Propriedade 7 (Seara), apresentou os sinais clínicos aproximadamente 20 minutos após o fim da administração, e foi tratado com azul de metileno a $1 \%$, na dose de $2 \mathrm{mg} / \mathrm{kg}$, por via endovenosa. 10 minutos após a aplicação apresentava-se alerta. Decorridos mais 20 minutos, levantou normalmente e assim permaneceu até o dia seguinte, quando voltou a se alimentar.

O Bovino141 recebeu por três dias, aveia verde proveniente de uma propriedade do município de Seara, onde uma vaca havia adoecido com sinais clínicos compatíveis com intoxicação por nitrato e teve melhora rápida após tratamento com azul de metileno. Nenhuma alteração clínica foi observada no Bovino 141.

Os resultados experimentais estão delineados no Quadro 3.

\section{DISCUSSÃO}

Neste estudo foram caracterizados a epidemiologia, os sinais clínicos e as lesões da intoxicação por nitrato/nitrito em bovinos alimentados com aveia (Avena sativa) e/ou azevém (Lolium spp.). Em situações semelhantes essa enfermidade foi diagnosticada no estado da Paraíba em bovinos alimentados com capim elefante (Pennisetunn purpureum) e capim mandante (Echinochloa polystachya) (Medeiros et al. 2003).

O quadro clínico obtido no estudo experimental e observado na doença espontânea foi idêntico aos descritos na literatura (Thorp Jr 1937, Bradley et al. 1939, O'Hara \& Fraser 1975, Egyed \& Shlosberg 1980, Van Dijk et al. 1983, Boermans 1990, Tokarnia et al. 2000, Radostits et al. 2002, Medeiros et al. 2003, Ozmen 2003, McKenzie et al. 2004, McKenzie et al. 2009). Da mesma forma, as alterações macroscópicas encontradas em bovinos que morreram pelas intoxicações espontânea e experimental foram semelhantes às encontradas por outros autores (Newsom et al. 1937, Thorp Jr 1937, Egyed \& Shlosberg 1980, Carrigan \& Gardner 1982, Boermans 1990, Brown et al. 1990, Valli 1992, Yeruham et al. 1997, Radostits et al. 2002, Medeiros et al. 2003, Ozmen 2003, Mckenzie et al. 2004). No entanto, somente Thorp Jr (1937) descreve coloração vermelho intenso dos músculos cardíacos e esqueléticos (cor de cereja) e Davidson et al. (1941), descrevem coloração vermelho intenso da musculatura esquelética.

0 principal pigmento da musculatura é a mioglobina.
Em presença de nitrito e outros subprodutos de reação deste composto, os pigmentos da musculatura podem sofrer numerosas alterações que dependem de fatores intrínsecos ( $\mathrm{pH}$, potencial de óxido-redução, atividade enzimática) e extrínsecos (aditivos, acidificação e aquecimento). Como o nitrito é um agente oxidante da mioglobina, provavelmente a reação inicial consiste na conversão da mioglobina e oximioglobina em metamioglobina. 0 óxido nítrico pode combinar-se com a metamioglobina originando a nitrosometamioglobina, que pode reduzir-se ao nitrosomioglobina que dá a coloração vermelha mais intensa da musculatura (Roça 2000). Os bovinos que morreram através de experimentação e que morreram pela doença espontânea, todos apresentaram coloração vermelha intensa do miocárdio esquerdo e da musculatura esquelética. Dessa forma, é provável que todos esses animais morreram em decorrência da ação do nitrito oriundo da transformação do nitrato em nitrito e não pelo efeito direto do nitrato, apesar de que um bovino (Bov.139) tinha coloração vermelho intenso da mucosa do abomaso. Essa alteração é atribuída ao efeito do nitrato (Radostits et al. 2002).

Tokarnia et al. (2000) descrevem que a carcaça recém-aberta exala um cheiro forte de gases nitrosos. Nos animais necropsiados durante o presente estudo, o odor forte das carcaças sempre estava presente, o que esta de acordo com informações de veterinários que realizaram necropsias de bovinos que morreram por essa enfermidade.

Ao exame histológico de amostras de vísceras dos bovinos que morreram pela intoxicação espontânea e experimental não foram encontradas lesões. A ausência de lesões microscópicas também é descrita por outros autores (Carrigan \& Gardner 1982, Van Dijk 1983, Boermans 1990, Choon et al. 1990, Riet-Alvariza 1993, Cheeke 1998, Tokarnia et al. 2000, Radostits et al. 2002, Medeiros et al. 2003, Ozmen 2003, Mckenzie et al. 2004, McKenzie et al. 2009).

0 tratamento com azul de metileno a $1 \%$ é descrito como o antídoto específico para a intoxicação por nitrito (Van Dijk et al. 1983, Boermans 1990, Yeruham et al. 1997, Radostits et al. 2002). 0 azul de metileno combina-se com a enzima metemoglobina redutase e tem ação de carrear elétrons para o substrato metemoglobina, que por redução converte a metemoglobina em hemoglobina (Van Dijk et al. 1983). Os bovinos intoxicados espontaneamente que receberam azul de metileno a $1 \%$, na dose de $4 \mathrm{mg} / \mathrm{kg}$ de peso vivo por via intravenoso (PV/IV) e o bovino submeti- 
do a experimentação que recebeu azul de metileno a $1 \%$ na dose de $2 \mathrm{mg} / \mathrm{kg}$ PV/IV apresentaram melhora, em poucos minutos após a aplicação; levantaram-se e mostraram apetite. Dependendo da quantidade de nitrato e conseqüentemente nitrito convertido no rúmen e a formação de metemoglobina pode-se aumentar essa dose até $20 \mathrm{mg} / \mathrm{kg} \mathrm{PV}$, porém elevadas doses de azul de metileno podem causar metemoglobinemia (Radostits et al. 2002).

0 aborto é registrado com freqüência, como seqüela em surtos de intoxicação; é possível que episódios de anóxia grave possam causar danos ao feto (Radostits et al. 2002). Yeruham et al. (1997) descrevem que vacas prenhas que adoeceram e não morreram, abortaram após o sexto dia da ocorrência do surto. Informações obtidas dos produtores referem-se a casos de aborto em vacas que pastoreavam em pastagem onde ocorreram casos de intoxicação por nitrato/nitrito.

No estado de Santa Catarina, a intoxicação por nitrato/ nitrito pode ser considerada como doença emergente. A enfermidade foi diagnosticada pela primeira vez em 2006 e a ocorrência anual de novos surtos aumentou gradativamente. A doença ocorre em diferentes regiões do Estado sempre que há adubação química e/ou orgânica excessiva. A maior parte dos surtos se concentrou na região oeste, e se caracterizou por uso de matéria orgânica, geralmente esterco de suínos e ou de aves e ainda por excessiva adubação nitrogenada.

As propriedades de Santa Catarina, em sua maioria, são pequenas áreas, com pecuária e agricultura, onde há a necessidade do máximo aproveitamento das áreas disponíveis. As propriedades não são mantidas somente para produção de leite, mas há integração de suínos e/ou, de aves, o que proporciona quantidades elevadas de esterco, o qual é utilizado em excesso sobre as pastagens, a fim de maior aproveitamento das áreas disponíveis para pastejo. 0 uso excessivo de matéria orgânica contribui para o acúmulo de nitrato em algumas plantas. Além desta prática, as freqüentes estiagens que acometem a Região Oeste, contribuem significativamente para a ocorrência de surtos de intoxicação por nitrato/nitrito. 0 uso excessivo de matéria orgânica e a escassez de chuvas são fatores fundamentais para o acúmulo de nitrato em algumas plantas (Rosenberger 1975, Riet-Alvariza 1993, Cheeke 1998, Radostits et al. 2002).

Segundo Ozmen (2003), durante a seca há baixa disponibilidade de água no solo comprometendo a absorção de nutrientes pelas plantas. Após a chuva o crescimento das plantas é acelerado e estas incorporam grande quantidade de nitrato que não é transformado em aminoácidos, proteínas e outros compostos nitrogenados. Nessas situações há maior acúmulo de nitrato nas plantas que, se ingeridas pelos animais, pode causar alterações clínicas e morte. O'Hara \& Fraser (1975), relatam que as intoxicações por nitrato/ nitrito podem ocorrer principalmente em períodos com dias chuvosos, com poucas horas de sol e baixas temperaturas. Essas alterações climáticas ocorreram no estado de Santa Catarina durante o inverno e primavera dos anos de 2008 e 2009, o que pode ter contribuído para um maior número de casos de intoxicação por nitrato/nitrito nesse pe- ríodo. Em 2010, a ocorrência de mortes por intoxicação por nitrato/nitrito foi menor que nos últimos quatro anos. Isto pode ser explicado pela não ocorrência de período seco durante o inverno e a primavera. Também pode ter contribuído para este fato, o baixo desenvolvimento das pastagens de inverno, que por motivos não conhecidos, foi verificado em todo o estado.

Os demais surtos verificados nas regiões do Alto Vale do Itajaí e do Planalto Serrano estão relacionados ao uso de adubação química excessiva. Essa afirmação esta respaldada em observações de outros autores que também citam o uso excessivo de adubo químico rico em nitrogênio como causa de acúmulo de nitrato em plantas, entre elas a aveia e o azevém (Newsom et al. 1937, Bradley et al. 1939, Cheeke 1998, Radostits et al. 2002, Villar et al. 2003, Kozloski 2009).

A água também pode conter teores elevados de nitrato, quando esta possuir elevados teores de matéria orgânica (Rosenberger 1975, Radostits et al. 2002), ou quando contaminada por fertilizantes (Rosenberger 1975, Yeruham et al. 1997, Cheeke 1998, Radostits et al. 2002, Villar et al. 2003). Em duas propriedades, uma no município de Rio do Sul (Propriedade 1) e outra em Seara (Propriedade 6), foi verificado que a água consumida pelos bovinos continha matéria orgânica e os níveis de nitrato foram de 7,2ppm e 8,5ppm respectivamente. É possível que bovinos que ingiram alimentos que contenham valores significativos de nitrato, mesmo não suficientes para produzir a doença, mas se ao mesmo tempo beberem água também com concentrações de nitrato, que a soma desse elemento pode resultar em intoxicação.

Em bovinos, o nitrato ingerido é convertido em nitrito (Wang et al. 1961, Kozloski 2009). 0 nitrito é responsável pela transformação da hemoglobina em metemoglobina e o pico de metemoglobinemia ocorre, ao redor de cinco horas após a ingestão do nitrato (Boermans 1990, Ozmen 2003). 0 tempo de apresentação da doença até a morte varia conforme a quantidade de nitrato ingerida e a quantidade de metemoglobina formada. Com valores de $50-60 \%$ de metemoglobina começam a ser observados sinais de falta de oxigênio nos bovinos, e os casos fatais ocorrem com $80 \%$ de metemoglobina (Rosenberger 1975). Na maioria das propriedades onde a enfermidade ocorreu, os animais eram soltos nas pastagens pela manhã e quando recolhidos á tarde, encontravam-se animais mortos, ou, alguns apresentavam cansaço, respiração ofegante, conjuntiva marrom, urinavam com freqüência e morriam entre 15 a 30 minutos.

Os animais acometidos eram as melhores vacas, produtoras de leite, ou novilhas com fome. Isto pode ser explicado que nessas circunstâncias os animais ingerem maior volume de pasto e conseqüentemente maior quantidade de nitrato. $\mathrm{O}$ fornecimento de outros alimentos, como silagem e rações antes de colocar os animais em pastagens de risco, pode evitar a ocorrência da enfermidade. Segundo Radostits et al. (2002), dietas ricas em carboidratos diminuem o risco de intoxicação e animais adaptados gradualmente podem ingerir dietas com até $8 \%$ de nitrato de potássio na MS.

Os testes da difenilamina realizados nas pastagens onde ocorreram surtos, foram positivos, obtendo-se coloração 
azul forte em menos de 10 segundos. Esse mesmo teste realizado em pastagens sem o histórico da enfermidade, resultou negativo ou, apenas em reações levemente azul. Isso pode ser confirmado pelos resultados do teor de nitrato de amostras de pastagens obtidas através de exame bromatológico, onde amostras com valores menores, de $3003,54 \mathrm{ppm}$ ou $0,3 \%$ de nitrato na matéria seca (MS) tiveram reação positiva para o teste de difenilamina. O'Hara \& Fraser (1975), encontraram amostras positivas em pastagens com níveis de nitrato de $0,5 \%$ na MS. Dessa forma o teste da difenilamina pode se tornar um grande aliado para indicar o nível de nitrato nas pastagens, antes que estas sejam utilizadas na alimentação de bovinos.

Teores de nitrato de potássio nas plantas acima de 1,5\% (Radostits et al. 2002) ou de 0,5 a 4,0\% de nitrato (Rosenberger 1975), podem produzir intoxicação em bovinos. As análises das amostras do presente estudo, pela técnica de destilação, revelaram teores de nitrato que variaram de 0,30 a 3,36\%. Essa concentração indica que em todas as propriedades onde ocorreram os surtos as pastagens eram potencialmente tóxicas.

Amostras coletadas de duas propriedades da Região Serrana, que tiveram históricos de bovinos com manifestação de timpanismo quando colocados em pastagem de aveia, tiveram concentrações 0,4563 e $0,4076 \%$ de nitrato na MS. Este fato sugere que essas concentrações de nitrato estariam no limite da quantidade necessária para causar intoxicação em bovinos. Esses valores são semelhantes aos descritos por Rosenberger (1975) que indica que as concentrações mínimas de nitrato na matéria seca das plantas suficiente para causar intoxicação estão entre 0,5 e 4,0\%.

0 diagnóstico da intoxicação por nitrato/nitrito pode ser efetuado através da epidemiologia, sinais clínicos, lesões encontradas na necropsia, teste de difenilamina na pastagem e análise da concentração de nitrato nas pastagens. As alterações de necropsia são sugestivas, desde que feita logo após a morte do animal, uma vez que algumas horas após a morte do animal a metemoglobina retorna a hemoglobina, desaparecendo a coloração escura do sangue, da carcaça e musculatura (Newsom et al. 1936, Cawley et al. 1977, Boermans 1990, Brown et al. 1990, Valli 1992, Tokarnia et al. 2000). Esses fatores dificultam a formação do diagnóstico, principalmente se a necropsia não for realizada rapidamente após a morte.

Agradecimentos.- À Universidade do Estado de Santa Catarina pelo apoio financeiro ao projeto. À CAPES, pela conceção de Bolsa de mestrado. Aos Médicos Veterinários Eduardo Perez e Kátia Sbruzi pelas informações e auxilio na realização desse trabalho e aos Engenheiros Agrônomos Jovani Zalamena e Fabricio T. Barbosa pelo auxílio nas análises de nitrato.

\section{REFERÊNCIAS}

Allison M.J. 1978. The role of ruminal microbes in the metabolism of toxic constituints from plant, p.101-118. In: Keeler R.F., Van Kampen K.R. \& James L.F. (Eds), Effects of Poisonous Plants on Livestock. Academic Press, New York.

Bradley W.B., Beath O.A. \& Eppson H.F. 1939. Oat hay poisoning. Science 21:365.

Boermans H.J. 1990. Diagnosis of nitrate toxicosis in cattle, using biological fluids and a rapid chromatographic method. Am. J. Vet. Res. 51(3):491-495.
Brown C.M., Burrows G.E. \& Edwards W.C. 1990. Nitrate intoxication. Vet. Human.Toxicol. 32(5):481-482.

Carrigan M.J. \& Gardner I.A. 1982. Nitrate poisoning in cattle fed sudax (Sorghum sp. hybrid) hay. Aust. Vet. J.59:155-157.

Cawley G.D., Collings D.F. \& Dyson D.A. 1977. Nitrate poisoning. Vet. Rec. 101:305-306.

Cheeke P.R. 1998. Natural Toxicans in Feeds. Forages, and Poisonous Plants. $2^{\text {nd }}$ ed. Interstate Publishers, Illinois.

Davison W.B., Doughty J.L. \& Bolton J.L. 1941. Nitrate poisoning of livestock. Can. J. Comp. Med. 5(11):303-313.

Egyed M.N. \& Shlosberg A. 1980. Ammonium nitrate poisoning in a herd of cattle. Refu. Vet. 37:101-103.

Jones T.C., Hunt R.D. \& King N.W. 2000. Moléstias decorrentes de substâncias tóxicas e venenosas estranhas, p.705-794. In: Ibid. (Eds), Patologia Veterinária. $6^{\underline{a}}$ ed. Manole, Barueri.

Kozloski G.V. 2009. Bioquímica Microbiana Ruminal, p.11-66. In: Ibid. (Ed), Bioquímica dos Ruminantes. Editora da Universidade Federal de Santa Maria, Santa Maria.

McKenzie R.A., Rayner A.C., Thompson G.K., Pidgeon G.F. \& Burren B.R. 2004. Nitrate-nitrite toxicity in cattle and sheep grazing Dactylotenium radulans (button grass) in stockyards. Aust. Vet. J. 82(10):630604.

McKenzie R.A., Gordon A.N., Burren B.G., Gibson J.A. \& Gardner M.P. 2009. Alpaca plant poisonings: nitrate-nitrite and possible cyanide. Aust. Vet. J. 87(3):113-115.

Medeiros R.M.T., Riet-Correa F., Tabosa I.M., Silva Z.A., Barbosa R.C., Marques A.V.M.S. \& Nogueira F.R.B. 2003. Intoxicação por nitratos e nitritos em bovinos por ingestão de Echinochloa polystachya (capim-mandante) e Pennisetum purpureum (capim-elefante) no sertão da Paraíba. Pesq. Vet. Bras. 23(1)17-20.

Newsom I.E., Stout E.N., Thorp Jr F., Barber C.W. \& Grouth A.H. 1937. Oat hay poisoning. J. Am. Vet. Med. Assoc. 90:66-75.

O’Hara P.J. \& Fraser A.J. 1975. Nitrate Poisoning in Cattle grazing crops. N. Z. Vet. J. 23(4):45-53.

Ozmen 0. 2003. Nitrate poisoning in cattle fed Chenopodium album hay. Vet. Human. Toxicol. 45(2):83-84.

Prophet E.B., Mills B., Arrington J.B. \& Sobin L.H. 1992.Laboratory Methods in Histotechnology. American Registry of Pathology, Armed Forces Institute of Pathology, Washington, DC. 279p.

Roça A.R.O. 2000. Tecnologia da carne e produtos derivados. Faculdade de Ciências Agronômicas, Unesp, Botucatu. 202p.

Radostits O.M., Gay C.C., Blood D.C. \& Hinchcliff K.W. 2000. Doenças causadas por toxinas de plantas, fungos, cianofitas, clavibactéria e por venenos de carrapatos e animais vertebrados, p.1472-1547. In: Ibid. (Eds), Clínica Veterinária: um tratado de doenças dos bovinos, ovinos, suínos, caprinos e eqüinos. 9a ed. Guanabara Koogan, Rio de Janeiro.

Riet-Alvariza F. 1993. Intoxicação por nitratos e nitritos, p.291-297. In: Riet-Correa F., Méndez M.C. \& Schild A.L. (Eds), Intoxicações por Plantas e Micotoxicoses em Animais Domésticos. Vol.1. Editorial Agropecuaria Hemisferio Sur, Montevideo.

Rosenberger G. 1975. Avvelenamenti, p.1120-1364. In: Ibid. (Ed.), Malattie del Bovino. Essegivi, Piacenza.

Tedesco M.J., Gianello C., Bissani C.A., Bohnen H. \& Volkweiss S.J. 1995. Análises de solo, plantas e outros materiais. Boletim Técnico de Solos, 5. Faculdade de Agronomia, Universidade Federal do Rio Grande do Sul, Porto Alegre.

Thorp Jr F. 1937. Further observations on oat hay poisoning. J. Am. Vet. Med. Assoc. 92:159-170.

Tokarnia C.H., Döbereiner J. \& Peixoto P.V. 2000. Plantas que causam intoxicação por nitratos/nitritos, p.222-224. In: Ibid. (Eds), Plantas Tóxicas do Brasil. Editora Helianthus, Rio de Janeiro.

Valli V.E.O. 1992. The hematopoietic system, p.101-265. In: Jubb K.V.F., Kennedy P.C. \& Palmer N. (Eds), Pathology of Domestic Animals. Vol.3. $4^{\text {th }}$ ed. Academic Press, San Diego. 
Van Dijk S., Lobsteyn A.J.H., Wensing T. \& Breukink H.J. 1983. Treatment of nitrate intoxication in a cow. Vet. Rec. 112(12):272-279.

Villar D., Schwartz K.J., Carson T.I., Kinker J.A. \& Barker J. 2003. Acute poisoning of cattle by fertilizer-contaminated water. Vet. Human Toxicol. 45(2):88-90.

Wang L.C., Garcia-Rivera J. \& Burris R.H. 1961. Metabolism of nitrate by cattle. Biochem. J. 81(237):237-242.
Wright M.J. \& Davison K.L. 1964. Nitrate accumulation in crops and nitrate poisoning in animals. Adv. Agron. 16:197-247.

Yeruham I., Shlosberg A., Hanji V., Bellaiche M., Marcus M. \& Liberboim M. 1997. Nitrate toxicosis in beef and dairy cattle herds due to contamination of drinking water and whey. Vet. Human Toxicol. 39(5):296-298.

Yong C., Brandow R.A. \& Howlett P. 1990. An unusual cause of nitrate poisoning in cattle. Can. Vet. J. 31:118. 